\title{
SANGRE AZUL, CALCO SEMÁNTICO Y ETIMOLÓGICO. DESARROLLO DE UNA IDEA DE EUGENIO COSERIU*
}

\author{
JAIro JAVIER García SÁNCHEZ \\ Universidad de Alcalá
}

\section{RESUMEN}

En el archivo de Eugenio Coseriu hay un material inédito, consistente en algunas notas, referencias y comentarios, sobre el origen de la expresión española sangre azul ('linaje noble'). Las notas son escuetas, pero suficientes para entender cómo veía el gran lingüista la explicación de la colocación, que se repite, como calco semántico, en otras muchas lenguas. Gracias a esas notas y al desarrollo de este trabajo a partir de ellas, se puede afirmar que la interpretación errónea de un texto de Tácito en las traducciones de humanistas españoles de comienzos del siglo XVII es la responsable del origen y arraigo de la expresión y de su consiguiente propagación.

La explicación filológica de E. Coseriu pone en evidencia la vacuidad de otras interpretaciones, a menudo peregrinas, que se han dado con afán más voluntarioso que realista; en particular, la que da una explicación sociológica y étnica del origen de sangre azul, consistente en que la piel pálida, no curtida por el trabajo en el campo, de los aristócratas y miembros de la realeza, sobre todo si eran de linaje godo, deja traslucir el color azulado de sus venas.

Palabras clave: sangre azul, Coseriu, colocación, traducción, polisemia, etimología popular, calco semántico.

\begin{abstract}
In the archives of Eugenio Coseriu, there is inedited material to be found in the form of notes, references and comments on the Spanish expression sangre azul 'blue blood' (noble lineage). His notes are brief, but sufficient enough for us to understand how the great linguist saw the explanation of the collocation, which repeats itself, as a semantic calque, in many other languages. Thanks to these notes and the development of the present study based on their content, it may be suggested that it is the erroneous interpretation of a section of Tacitus in the translations of Spanish Humanists dating from the beginning of the $17^{\text {th }}$ Century, to which the expression owes its roots and origin, as well as its subsequent propagation.

The philological explanation of E. Coseriu exposes the shallowness of other interpretations, often outlandish and more wayward than realistic; in particular, the interpretation given by a sociological and ethnic explanation of the origin of

\footnotetext{
* Este trabajo se inserta en el marco del proyecto de investigación Lingüistica de E. Coseriu y lingüistica coseriana (Ref. FFI2008-04605/FILO).
} 
sangre azul, based on the fact that the pale skin, that is not weather-beaten by working in the fields, of aristocrats and members of the royal family, especially if they are of Gothic descent, shows the blue colour of their veins.

Key Words: Blue blood, Coseriu, collocation, translation, polysemy, folk etymology, semantic calque.

RECIBIDO: 27/04/2010

APROBADO: 27/05/2010

Entre el numeroso material inédito del archivo de Eugenio Coseriu hay unas pocas fichas manuscritas con notas, referencias y comentarios sobre el posible origen de la expresión española, bien conocida, sangre $a z u l^{1}$.

La fórmula se repite en otras muchas lenguas europeas, como el francés (sang bleu), el italiano (sangue blu), el portugués (sangue azul), el rumano (sânge albastru), el catalán (sang blava), el inglés (blue blood), el alemán (blaues Blut), el holandés (blauw bloed), el sueco (blått blod), el ruso (голубая кровь [golubaya krov']), el polaco (btękitna krew), el húngaro (kékvérü), el finés (siniverisyys), etc., pero, según es comúnmente aceptado, son todas, en última instancia, traducciones de la expresión española. Parece que, en efecto, sangre azul, originaria de Castilla, se irradió como calco a los demás idiomas.

Las notas de Coseriu son ciertamente escuetas, pero se interpretan sin dificultad y resultan suficientes, siguiendo la pista que ofrecen, para permitimos entender cómo veía el insigne maestro la explicación de la expresión.

\section{LA COLOCACIÓN SANGRE AZUL}

Como es sabido, el sintagma sangre azul equivale en su significado a 'linaje noble' y con ese valor aparece recogido en buena parte de los diccionarios al uso. Sin ir más lejos, en el DRAE, s.v. sangre, es la primera de las expresiones usuales incluidas tras las acepciones generales de la palabra que forma su base ${ }^{2}$.

De acuerdo con la terminología actual de análisis fraseológico, sangre azul es una colocación. La «colocación» es la propiedad de las lenguas por la que los hablantes tienden a producir ciertas combinaciones

${ }^{1}$ Las fichas están archivadas bajo la rúbrica «Lingüística románica: etimología de modismos» en el Archivo de E. Coseriu en la Universidad de Tubinga. Agradezco al Dr. Reinhard Meisterfeld que me haya facilitado una copia de las mismas.

${ }^{2} \mathrm{Al}$ menos hasta la $22^{\underline{a}}$ ed. del $D R A E$, ya que en la $23^{\underline{a}}$ ed., cuyo avance se ha podido consultar en internet <www.rae.es $>$ durante la elaboración de este artículo, aparece detrás de buena y mala sangre. 
de palabras concretas, dentro de un alto número teóricamente posible; y asimismo se llama con ese nombre -colocaciones- a las combinaciones resultantes de, al menos, dos unidades léxicas en relación sintáctica, que no constituyen, por sí mismas, actos de habla ni enunciados, y que, debido a su fijación en la norma, presentan restricciones de combinación establecidas por el uso ${ }^{3}$.

Una colocación consta de base colocante (sangre) y colocativo (azul); el primero es el elemento principal, capaz de admitir colocativos diferentes (sangre azul, sangre noble, sangre plebeya; sangre caliente, sangre frí, etc.). Otras unidades fraseológicas, como la locución (a sangre fría 'con premeditación y cálculo') y el enunciado (la sangre se hereda y el vicio se pega) muestran mayor fijación expresiva.

Sangre azul es, pues, una colocación que responde al esquema «sustantivo + adjetivo», muy común en español y en otras lenguas. En función del grado de restricción entre las unidades colocadas, sería una «colocación restringida», donde la acepción de un elemento viene determinada por el otro ${ }^{4}$.

Uno y otro elemento no tienen el mismo estatus semántico, ya que la base presenta autonomía semántica, determina la elección de su colocativo y selecciona con frecuencia en él una acepción especial -generalmente de carácter abstracto o figurativo-, que este presenta únicamente en coaparición con ella. Estas condiciones se cumplen también en el caso de sangre azul.

De hecho, podemos corroborar que sangre azul, como colocación que es, participa de todas o casi todas las características lingüísticas propias de las unidades fraseológicas ${ }^{5}$ :

- notable frecuencia de uso, que ha permitido convertirla en una expresión estable, si bien la coaparición conjunta de sus elementos integrantes no es mayor que la aparición individual de cada palabra en la lengua;

- institucionalización, motivada por la frecuencia y uso repetido, y entendida en términos de fijación (estabilidad formal) y especialización semántica (lexicalización), que favorecen su reproducibilidad;

${ }^{3}$ Cf. Corpas Pastor 1996, p. 66 y 2003, pp. 74 ss.

${ }^{4}$ De acuerdo con este mismo criterio, las colocaciones son libres, restringidas, estables y habría, además, una categoría puente entre las colocaciones y las expresiones idiomáticas. Cf. Corpas Pastor 1996, pp. 80 ss.

${ }^{5}$ V. Corpas Pastor 1996, pp. 19 ss.; 1998, pp. 167 ss.; 2003, pp. 69 ss. La autora confirma la condición de unidades fraseológicas de pleno derecho para las colocaciones, precisamente porque contienen sus rasgos distintivos: polilexicalidad, alta frecuencia de aparición y de coaparición, institucionalización, estabilidad (fijación y especialización semántica), idiomaticidad y variación potenciales. 
- idiomaticidad, siendo este un rasgo potencial de las unidades fraseológicas -al igual que la variación-, que en sangre azul se ha hecho efectivo por su significado traslaticio ('linaje noble'). Es evidente que el significado global de la unidad fraseológica no es deducible del significado aislado de cada uno de sus elementos constitutivos (sangre azul $\neq$ sangre + azul). La unidad es idiomática por ese significado metafórico, y también lo es por el sentido etimológico propio y peculiar de una lengua determinada, en este caso, la española.

Si analizamos otros aspectos, comprobamos que la colocación sangre azul no ofrece apenas variación léxica, pues no tiene variantes claramente establecidas. Estirpe, linaje, familia son voces que podrían ser variantes de sangre al cumplir las condiciones precisas para ello, pero no son fijas y no forman una serie limitada y estable con ella en su combinación con $a z u l$. Lo mismo o más podemos decir de las posibles variantes de azul; solo noble podría apuntarse como variante (sangre noble), pero tampoco llega a equipararse a $a z u l^{6}$.

Tampoco hemos anotado ejemplos de modificaciones o desautomatizaciones de la colocación en el discurso, sin que esto signifique que no se hayan producido. Sí podemos señalar, en cambio, alguna nueva creación colocacional surgida a partir del modelo de sangre azul. Tal es el caso de príncipe azul, que responde al mismo esquema de «sustantivo + adjetivo", donde la base -el sustantivo-, que posee autonomía semántica, selecciona para el colocativo -el adjetivo azul-, elegido por clara analogía, una acepción figurada similar a la que muestra en sangre $a z u l^{7}$.

\section{ORIGEN DE SANGRE AZUL}

Lógicamente es la segunda acepción de la palabra sangre ('linaje' o 'parentesco'), de claro carácter figurado a partir de la primera ('líquido, generalmente de color rojo, que circula por las arterias y venas del cuerpo de los animales'), de la que se debe partir para comenzar a desentrañar la expresión. El paso del primer significado al segundo no plantea apenas problemas, por lo que no me detendré en ello (cf. otras expresiones como llevar (algo) en la sangre 'ser innato o hereditario' o carne y sangre 'hermanos y parientes', que pueden servir para explici-

\footnotetext{
${ }^{6}$ Notemos que no es el mismo caso que el de «todo queda en casa/en familia», señalado por Corpas Pastor 1996, p. 28.

${ }^{7}$ Nótese que esta nueva colocación en español, a diferencia de sangre azul, no encuentra su paralelo exacto en las demás lenguas (cf. fr. prince charmant, ingl. prince charming...). En alguna, como el italiano, sí lo tenemos (principe azzurro).
} 
tar la polisemia). Sin duda ese segundo significado, que se mantiene en la palabra de manera individual -recordamos la autonomía semántica de la base en la colocación-, se ha visto potenciado por su arraigo en la expresión que aquí vamos a analizar, en las que acabo de mencionar, o en otras del tipo de (de) pura sangre, pureza/impureza de sangre y limpieza de sangre.

Mucho más interés y aparente complejidad presenta el paso de azul al significado de 'noble'. Para su aclaración nos vamos a servir de las notas y referencias de Coseriu, pero antes es conveniente revisar lo que se suele decir de la colocación y de su posible origen en los diccionarios y manuales.

\subsection{Explicación dada hasta ahora de la colocación}

En los diccionarios etimológicos españoles de referencia no se explica la expresión ${ }^{8}$. Tampoco lo hacen los diccionarios de la lengua usual o actual, aunque es cierto que ese no es propiamente su cometido; estos se limitan a dar su significado ${ }^{9}$ y, en ocasiones, a ejemplificarla ${ }^{10}$.

La motivación del uso de azul aplicado a sangre sí se expone, no obstante, en algunos manuales especializados, como, por ejemplo, el de Iribarren 1994, p. 338, donde se da cuenta de dos notas, aparecidas ya en el siglo XIX, con sendas explicaciones posibles. La primera señala que

se ha dicho que tienen sangre azul los individuos de la alta nobleza (no los hijosdalgo), para zaherir la vanidad de aquellos que no quieren tener ninguna cosa común con los hombres plebeyos, aunque por necesidad hayan de participar de muchas de ellas, como la de tener la sangre roja.

Sería en ese caso una designación despectiva en origen. La segunda, en cambio, apunta a que

la regla general es que las personas de linaje ilustre, por las riquezas que gozan, por la clase de vida que hacen y por otras razones de casta que entran

\footnotetext{
${ }^{8} \mathrm{Ni}$ en el $D C E C H$ de Corominas y Pascual 1980 ni en el diccionario etimológico de García de Diego 1985 se menciona sangre azul.

9 Cf., por ejemplo, el diccionario de María Moliner 1998, p. 1026, s.v. sangre: «SANGRE AZUL. Linaje noble».

${ }^{10}$ V., por ejemplo, el diccionario de Seco y otros 1999 I, p. 557, s.v. azul, donde se muestra mediante un texto de Delibes el uso del adjetivo azul junto a sangre con el valor de 'noble': «Ser de La Orotava equivale a ser descendiente de la pata del Cid, a tener la sangre azul. En la plaza de La Orotava, los nobles paseaban por un lado y por el otro los plebeyos». La misma cita se repite en el Diccionario fraseológico documentado del español actual, de los mismos autores (Seco y otros 2004, p. 911, s.v. sangre). Cf., asimismo, otros diccionarios de uso, como el Clave -Maldonado González (dir.) 1996, p. 1637, s.v. sangre-.
} 
bajo el dominio de la fisiología, son pálidos y de cutis tan transparente que permite ver y notar fácilmente el color azulado de sus venas. De aquí el origen de llamar gente de sangre azul a los de genérica estirpe o a los que se precian de un abolengo aristocrático.

Esta segunda argumentación parece haber contado con mayor aceptación, pues es, con diferencia, la más generalizada y extendida hoy en día. Así, en otras obras recientes, como la de Buitrago Jiménez 2002, p. 646, podemos leer que

se dice que tiene sangre azul o es de sangre azul quien desciende o dice descender de reyes o de nobles. Son aún muchos los que piensan que el principe heredero debería casarse con una mujer de sangre azul. En las cortes españolas de los siglos XVI y XVII se puso de moda la piel blanquísima, hasta el punto de que la familia real y los hombres y mujeres de altas clases sociales se protegían todo lo posible del sol para evitar que pudieran adquirir siquiera un mínimo tono moreno, propio del vulgo. Su piel extremadamente blanca, casi transparente, hacía que las venas se distinguieran perfectamente y que se vieran de un color más azulado de lo normal, a causa del contraste. Entre las clases más bajas se extendería entonces la creencia de que reyes y nobles, como otro rasgo diferenciador más, tenían la sangre azul o, al menos, diferente.

La explicación, fundamentada en ese hecho sociológico, se repite con ligeras variantes de manera dominante en cualquier foro, tanto de calado científico como de corte informal; y, por supuesto, es la que «reina» en Internet ${ }^{11}$.

Si trasladamos nuestra mirada a lo que se dice en las otras lenguas europeas de las respectivas colocaciones hermanas, veremos que, además de atribuirles procedencia hispánica, también coinciden en la motivación con lo apuntado hasta ahora. Como muestra, muy representativa, traemos aquí lo que se puede leer al respecto en el diccionario Oxford de la lengua inglesa:

blue blood: that which flows in the veins of old and aristocratic families, a transl. of the Spanish sangre azul attributed to some of the oldest and proudest families of Castile, who claimed never to have been contaminated by Moorish, Jewish, or other foreign admixture; the expression probably originated in the blueness of the veins of people of fair complexion as compared with those of dark skin; also, a person with blue blood; an aristocrat ${ }^{12}$.

Y, de igual manera, en el diccionario histórico de la lengua francesa:

${ }^{11}$ Cf. lo que se dice de ella en Wikipedia <http://es.wikipedia.org/wiki/Azul>: «La expresión de sangre azul quiere decir 'de familia aristocrática' o 'de familia real'. Esto se debía a que los aristócratas y miembros de la realeza no salían al campo a trabajar, por lo que solían tener la piel más pálida, a través de la cual se les podían ver las venas, que se muestran azules».

12 Cf. Simpson y Weiner 1989, II, p. 303, s.v. blood. 
Avoir du sang bleu «être de sang noble» (1817, Stendhal) est un emprunt tardif à l'espagnol sangre azul, expression attribuée à la noblesse castillane qui se larguait de ne pas s'être mésalliée avec les Maures ou les Juifs, et qui trouve sans doute son origine dans le fait que les veines des personnes de complexion délicate apparaissent nettement ${ }^{13}$.

Este tipo de argumentaciones parece haberse visto favorecido por la supuesta vinculación de sangre azul con sangre goda ${ }^{14}$, expresión atestiguada desde época más antigua, y que servía para poner especial énfasis en la distinción entre el cristiano viejo y el moro o judío. El cristiano viejo podía considerarse descendiente de los visigodos, y sería, por ello, de tez mucho más clara. A este respecto, resulta también interesante lo que se señala en el Nordisk familjebok sueco:

Blått blod, ett på senaste tiden i bruk kommet uttryck, liktydigt med «gammal adel», hvilket lär härleda sig från Spanien, der man med sangre azul 'azurblått blod' under morernas tid betecknade den vestgotiska adeln med dess hvita hy och blått genomskimrande ådror i motsats till morerna med deras mörka hudfärg ${ }^{15}$.

\subsection{Los datos coserianos}

Expuestas las consideraciones generales sobre la colocación y su motivación, es el momento de hacer uso de las notas de Coseriu para tratar de aclarar su verdadero origen. De entre las fichas manuscritas del romanista rumano-uruguayo destacan las que hacen referencia a la traducción en la primera mitad del siglo XVII de un texto de Tácito -y en concreto, de unas líneas- por parte de algunos humanistas españoles -en realidad, sus primeros traductores al castellano-, como Baltasar Álamos de Barrientos, Antonio de Herrera, Emanuel Sueyro o Carlos Coloma. Además, se puede ver una pequeña recopilación de una misma serie de acepciones del adjetivo celeste, en la que este se identifica con el color azul o remite a él ${ }^{16}$, y también alguna referencia biblio-

\footnotetext{
${ }^{13}$ Cf. Rey 1998, p. 3376, s.v. sang. Dworkin 2006, p. 78 ya manifiesta sus dudas sobre esta hipótesis.

${ }^{14} \mathrm{~V}$. al respecto el ejemplo de la nota 17.

15 «Sangre azul, una expresión que recientemente se ha hecho popular, equivale a "nobleza antigua", la cual se dice que proviene de España, donde se usaba sangre azul durante la época de los moros para denominar la nobleza visigoda con su piel blanca y las venas azules que brillaban por la piel a diferencia del color oscuro de la piel de los moros.» Cf. Westrin 1896, p. 946, s.v. Blått blod.
}

16 Así, por ejemplo, en la segunda acepción del DRAE, s.v. celeste. 
gráfica que incluye ejemplos de sangre azul, como la del diccionario de Antonio de Pagès ${ }^{17}$. También se menciona su explicación más común, recogida, entre otros, por el diccionario Oxford, tal como ya hemos visto.

El texto traducido de Tácito pertenece al libro IV de los Anales y se sitúa en un pasaje en el que Agripina, tras haber sido acusada de adulterio Claudia Pulcra, va a ver a Tiberio, a quien halla realizando un sacrificio a Augusto:

Agripina semper atrox, tum et periculo propinquae accensa, pergit ad Tiberium ac forte sacrificantem patri repperit. quo initio invidiae non eiusdem ait mactare divo Augusto victimas et posteros eius insectari. non in effigies mutas divinum spiritum transfusum: se imaginem veram, caelesti sanguine ortam, intellegere discrimen, suscipere sordis ${ }^{18}$ (Tac., Ann. IV 52) ${ }^{19}$.

Agripina, siempre de carácter recio, e irritada entonces por el peligro de su pariente, se presentó ante Tiberio, que por casualidad hacía un sacrificio a su padre. Y de ahí toma motivo para reprocharle que no es propio que ofrezca víctimas al divino Augusto el mismo que persigue a sus descendientes; y que su divino espiritu no se habia transmitido a imágenes mudas; que ella, su imagen verdadera, nacida de su sangre celestial, entendía el peligro y tomaba el luto ${ }^{20}$.

La primera traducción castellana publicada de Tácito es la de Emanuel Sueyro. A esta le seguirán la de Baltasar Álamos de Barrientos, Antonio de Herrera y, un poco más tarde, por iniciativa de Fr. Leandro de San Martín, la de Carlos Coloma. Veamos ahora cómo tradujeron estos autores el texto en cuestión:

y que no estava en aquellas estatuas mudas el espíritu Divino, pero que la imagen verdadera de linage celestial era la que entendía esta diferencia, y sentía los daños de los suyos (Emanuel Sueyro) ${ }^{21}$.

Que no estava el divino espíritu metido, y derramado por los miembros de aquellas mudas estatuas, ni se avía passado a ellas: sino que la verdadera imagen, y el verdadero spirítu nacido de sangre celestial, era el que entendía la diferencia de aquellas cosas, y el que recebía, como si se hizieran contra el aquellas fealdades (Baltasar Álamos de Barrientos) ${ }^{22}$.

\footnotetext{
${ }^{17}$ Los ejemplos de sangre azul que aparecen en este diccionario, s.v. sangre, son de Vargas Ponce («No mi muger visite a todo el mundo/ De sangre azul por ser de sangre goda»), Bretón de los Herreros y R. José de Crespo.

18 La cursiva destaca el texto que aparece traducido en las notas de Coseriu.

19 Texto de la edición oxoniense de Fisher, 1906.

${ }^{20}$ La traducción es nuestra.

${ }^{21}$ Cf. Emanuel Sueyro, Las obras de Cornelio Tácito, traducidas de Latín en Castellano, Anvers, 1614, p. 161, BNE, R/6615.

22 Cf. Baltasar Álamos de Barrientos, Tácito español ilustrado con aforismos, Madrid, 1614, pp. 232-233, BNE, R/16431.
} 
¿No está aquel divino espíritu en las estatuas mudas? Su verdadera imagen, nacida de la sangre celestial, siente bien los peligros, y participa de mis desventuras (Antonio de Herrera) ${ }^{23}$.

Aquel divino espíritu no se ha transportado a las estatuas mudas; mas su verdadera imagen, nacida de la sangre celeste, siente bien mis peligros, y participa de mis miserias (Carlos Coloma) ${ }^{24}$.

Tal como se ve, para la traducción del latín caelesti sanguine (ortam), en referencia a la sangre o al linaje del divinizado Augusto, y, por tanto, del cielo, se han empleado las expresiones linaje celestial (Sueyro), sangre celestial (Álamos de Barrientos y Herrera), y finalmente sangre celeste (Coloma).

\subsection{Interpretación de los datos e hipótesis}

Esa última traducción, sangre celeste, es la que, sin duda, permite situarnos en la mejor disposición para lanzar la hipótesis coseriana. En efecto, la fácil e inmediata asociación de celeste, adjetivo relativo al cielo, con el color azul, por constituir ese color la cualidad descriptiva que enseguida lo caracteriza y, consecuentemente, por haber pasado el azul del cielo a definir una de las tonalidades de ese color ${ }^{25}$, pudo provocar que, a partir de este texto de Tácito y de su traducción, la expresión sangre celeste -en origen 'sangre, ascendencia divina, del cielo'- se llegara a interpretar como equivalente de sangre azul.

Hay que tener muy en cuenta las connotaciones divinas que tiene el color azul precisamente por su vinculación a lo celeste, a lo celestial, al cielo. Ya desde los tiempos del antiguo Egipto el azul se asociaba al cielo y a los dioses; la iconografía cristiana tiene muy presente el azul en sus representaciones; y la monarquía también lo hará suyo, con la intención de hacer ver así su origen divino, sobrehumano ${ }^{26}$. No cabe duda

${ }^{23}$ Cf. Antonio de Herrera, Los cinco primeros libros de los Annales de Cornelio Tácito, traducidos de lengua latina en castellana, Madrid, 1615, p. 75, BNE, R/2624.

${ }^{24}$ Cf. Tácito, Obras, trad. de Carlos Coloma, Douay, 1629, p. 248, BNE, R/5265.

${ }_{25}$ No en vano, tal como recoge el DRAE, s.v. celeste, la segunda acepción de este adjetivo, tras la de "perteneciente o relativo al cielo", es la que remite al color azul. Además, el DRAE, s.v. $a z u l$, define esta voz - azul- como «del color del cielo sin nubes» y, en una segunda acepción, «el cielo, el espacio».

${ }^{26}$ La monarquía capetiana francesa, aliada con la Iglesia, tomará para su escudo de armas un fondo de azur sobre el que se despliegan tres flores de lis doradas; reemplazará así el estandarte rojo de Hugo Capeto. El azul, al igual que el blanco, es percibido como símbolo de pureza porque el cielo, el éter, es concebido desde hace mucho tiempo como un refugio y como la residencia de lo sobrehumano. Cf. Rey 2005, p. 959, s.v. bleu. V. asimismo y especialmente Pastoureau 2000, pp. 50-63, quien expone con claridad cómo al final de la Edad Media el azul se había convertido en el color de los reyes, de los príncipes, de los nobles y de los patricios. 
de que todo ello contribuiría a hacer más natural y entendible el paso de la sangre celestial o celeste a azul.

Además de en español, en las otras lenguas románicas las voces cognadas del adjetivo celeste (fr. céleste, it. celeste, etc.) también han desarrollado la misma polisemia y pueden designar 'aquello que es de la naturaleza del cielo', como el color azul claro. Considerando que el adjetivo está asimismo presente en las traducciones del mismo texto tacitiano a esos otros idiomas (céleste sang, sangue celeste... ${ }^{27}$, la interpretación del adjetivo en esa expresión como 'azul' y no como 'relativo al cielo' pudo haber tenido lugar igualmente en cualquiera de esas lenguas de manera originaria.

No obstante, creemos, como Coseriu, que fue en español donde surgió la colocación y luego, ya sí, se extendió al resto de lenguas -tal como se piensa hasta ahora, aunque con una motivación bien diferente-. Comprobamos así que en la segunda mitad del siglo XVII -apenas medio siglo después de las señaladas traducciones al español- la colocación ya estaba plenamente constituida en el idioma. Eso es lo que nos muestra el CORDE con su primera documentación de sangre azul, donde aparece, en el año 1676, en un acta de la Junta de las cuatro villas de la Costa de la Mar:

Y de manera que siempre que entre nuebo corregidor, esté elegido el diputado general, y que aya de tener este cargo mientras el corregidor exerciere su oficio y con calidad que el dicho diputado general aya de ser persona noble, fijo de algo notorio de la sangre açul y suficiente para este exercicio y que en todas las Juntas Generales tenga asiento mas preeminente después de la justicia (Real Academia Española: Banco de datos (CORDE) [en línea]. Corpus diacrónico del español. <http://www.rae.es> [último acceso: abril de 2010])

Esta primera documentación es, cuando menos, bastante más temprana que las apuntadas para las demás lenguas.

\subsection{El «tacitismo» del Barroco y la popularización de la expresión}

Las traducciones de Tácito tuvieron una notable difusión en el siglo XVII, por lo que no debe extrañar que a partir de ellas -sobre todo de la de Coloma- acabara triunfando la imagen de la sangre celeste, como 'linaje divino, noble', convertida pronto en sangre azul.

La situación política y social de Europa había contribuido en gran medida a hacer de Tácito el historiador clásico preferido para muchos. El descubrimiento paulatino de su obra vino a coincidir con el nacimien-

\footnotetext{
27 Así se puede observar en las traducciones, también del siglo XVII, que hemos manejado en francés e italiano, como, por ejemplo, las de Perrot, Politi o Davanzati.
} 
to del Estado moderno. Tácito, en historia, junto a Séneca en filosofía, se convirtió en uno de los principales sabios en la época barroca ${ }^{28}$.

Desde luego el «tacitismo» fue una corriente de pensamiento europea, y no algo exclusivo de España ni tampoco con origen en suelo hispano. El tacitismo español fue importado, y ello se aprecia muy bien precisamente en las traducciones. Tal como expone Antón Martínez 1992, pp. 64 ss., existía cierto temor por trasladar al castellano a un historiador «impío y gentil» como Tácito. No obstante, ese temor se fue venciendo y la obra de Tácito acabó poniéndose en romance; los españoles, dentro de la línea intelectual europea, fueron los últimos en hacerlo, después de los italianos, franceses e ingleses. El propio Antonio de Herrera, uno de los traductores, confiesa que los españoles fueron los postreros.

Sanmartí 1951, p. 28 señala que «los autores españoles no se dedicaron a comentarios gramaticales a fin de mejorar la lectura de Tácito y facilitar su interpretación. Falta todo intento original de fijación de texto; los comentaristas se perdieron en insulsas consideraciones políticas, abrumando a Tácito con aforismos, consejas y comentarios a veces inútiles, cuando no disparatados» ${ }^{29}$.

No obstante, Antón Martínez 1992, p. 17 matiza que sí hubo trabajos filológicos españoles sobre Tácito en el siglo XVII: «Los españoles hicieron traducciones de Tácito, escolios, aclararon pasajes textuales; en fin, mostraron un claro interés filológico por Tácito, tanto más llamativo cuanto se descubre por temprano y prácticamente hasta ahora desconocido, aun cuando sea también verdad que lo abrumaron con comentarios políticos».

En cualquier caso, es cierto que -tal como corrobora Antón Martínez 1992, p. 63-, «nuestros humanistas de los siglos XVI y XVII no se preocuparon de sacar a la luz una edición crítica de Tácito. Y aquellos que por su erudición y afinado ingenio pudieron haberla llevado a cabo (por ejemplo Antonio Agustín o F. Sánchez de las Brozas), no lo hicieron. En ello debió influir sus prejuicios ciceronianos. Desde la primera edición de Tácito (Venecia, 1470) hasta los trabajos de Lipsio, Pichena y Grutero 1607, ningún español publicó una edición crítica de las obras del autor de los Annales, un comentario o una traducción. Tendremos que esperar hasta 1794 para encontrar una verdadera edición de Tácito, dentro de lo que se hacía a finales del siglo XviIr: la de C. Sixto y J. Ezquerra».

Esa edición, por cierto, se basa en la traducción de Carlos Coloma. Y es que la traducción de este escritor alicantino es la que contiene más errores -así se ha indicado-, pero su estilo fluido, claro, de más fácil

${ }^{28}$ Cf. Antón Martínez 1992, pp. 11 ss.

29 V. también Antón Martínez 1992, p. 13. 
y agradable lectura, más apartado de la austera concisión y sequedad sentenciosa tacitiana, la hacía preferible a cualquier otra. Ese hecho explica que fuera desde el principio muy popular y difundida, y que sus reimpresiones hayan llegado hasta nuestros días ${ }^{30}$. Ahí precisamente puede residir la clave del arraigo y especialización de sangre celeste, de sangre azul, como equivalente de 'sangre divina', o lo que es lo mismo, de la 'de más elevada alcurnia' ('sangre noble'). Parece claro que las primeras traducciones castellanas de Tácito, y en especial la de Coloma, con todas sus carencias y deficiencias, tuvieron, sin embargo, una importancia decisiva para la cuestión que nos ocupa.

\section{TRADUCCIÓN Y EXPANSIÓN DE LA COLOCACIÓN}

Tradicionalmente se ha considerado que era muy difícil, incluso imposible, traducir las unidades fraseológicas a otras lenguas, hasta el punto de que se ha llegado a contemplar la intraductibilidad como uno de sus rasgos propios. Sin embargo, aunque su traducción no esté exenta de dificultades, esto no es así, pues, de hecho, la fraseología se estructura de manera similar en muchas lenguas y se pueden establecer universales fraseológicos ${ }^{31}$.

Es más, en las lenguas europeas se dan con frecuencia paralelismos o coincidencias entre unidades fraseológicas que tienen una forma casi idéntica y significados similares. Por ello, se puede hablar de «europeísmos», que se caracterizan por compartir un origen común, bien sea como unidades genéticamente independientes, surgidas como «producto de la observación del mundo que nos rodea» (europeísmos naturales); o bien como genéticamente dependientes, por cuanto proceden «de fuentes comunes de la cultura europea» (europeismos culturales). Estos últimos pueden tener su origen en fragmentos de la Biblia, en la literatura clásica greco-romana, en los textos latinos medievales, en los repertorios de paremias traducidos a las lenguas vernáculas, y en la literatura y el folclore populares ${ }^{32}$.

Quizás sea demasiado osado incluir dentro de este último grupo de europeísmos culturales la colocación sangre azul, pero conviene tener en cuenta que esta combinación se repite en buena parte de las lenguas europeas. El hecho, según hemos expuesto aquí, responde probablemente a un calco de la expresión española surgida a partir de la traducción al español del texto de Tácito, con la consabida interpretación de celeste 'del cielo' por 'azul'.

\footnotetext{
30 V. Antón Martínez 1992, pp. 84 ss.

31 V. Corpas Pastor 2000, pp. 483 ss.

32 Cf. Corpas Pastor 2000, pp. 487 ss.
} 
En principio se trata de una equivalencia plena, pues la colocación parece presentar en las distintas lenguas el mismo significado denotativo y connotativo, la misma base metafórica, una similar distribución y frecuencia de uso, las mismas implicaciones convencionales, la misma carga pragmática y similares restricciones diastráticas, diafásicas y diatópicas. Este tipo de equivalencia es raro -son más frecuentes las equivalencias parciales-, pero se puede dar en determinados casos, como precisamente el de los europeísmos y los calcos ${ }^{33}$. El calco es curiosamente -así lo señala Corpas Pastor 2000, pp. 510 ss.- uno de los procedimientos más empleados para traducir la fraseología.

Terminamos este trabajo con la mención del adjetivo compuesto del griego moderno $\gamma \alpha \lambda \zeta o \alpha i ́ \mu \alpha \tau o s$ 'noble, de sangre azul', formado a

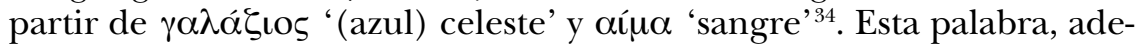
más de suponer un calco más de la expresión, viene a apoyar la hipótesis coseriana, pues el adjetivo que corresponde al primer elemento

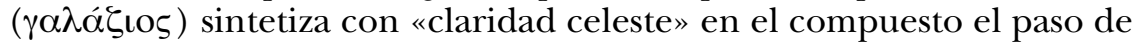
sangre celeste a azul.

En conclusión, las notas de Eugenio Coseriu permiten liberar la colocación sangre azul de las interpretaciones erróneas que reducen su origen a la expresión del aspecto físico del azul de las venas, y situarlo en el ámbito casi divino del azul del cielo. Dada la propagación de la expresión, así como de su falsa explicación, estamos, además, ante un interesante caso de calco semántico y calco etimológico, o de etimología popular, desde el español a las otras lenguas europeas.

\section{REFERENCIAS BIBLIOGRÁFICAS}

Antón Martínez, B. (1992): El Tacitismo en el siglo XVII en España. El proceso de la receptio, Valladolid, Universidad de Valladolid.

Buitrago Jiménez, A. (2002): Diccionario de dichos y frases hechas, Madrid, Espasa. Corominas, J. y Pascual, J. A. (1980): Diccionario crítico etimológico castellano e hispánico (DCECH), 6 vols., Madrid, Gredos.

Corpas Pastor, G. (1996): Manual de fraseología española, Madrid, Gredos.

- (1998): «Criterios generales de clasificación del universo fraseológico de las lenguas, con ejemplos en español y en inglés», en Alvar Ezquerra, M. y Corpas Pastor, G. (coords.), Diccionarios, frases, palabras, Málaga, Universidad de Málaga, pp. 157-187.

\footnotetext{
33 V. Corpas Pastor 2000, pp. 490-491.

${ }^{34}$ Agradezco a la profesora Angélica Alexopoulou, de la Universidad de Atenas, la oportuna indicación de este adjetivo del griego moderno.
} 
- (2000): "Acerca de la (in)traductibilidad de la fraseología», en Corpas Pastor, G. (ed.), Las lenguas de Europa: estudios de fraseología, fraseografía y traducción, Granada, Editorial Comares, pp. 483-522.

- (2003): «Apuntes para el estudio de la colocación», en Corpas Pastor, G., Diez años de investigación en fraseología: análisis sintáctico-semánticos, contrastivos y traductológicos, Madrid, Iberoamericana, Vervuert, pp. 67-81.

Dworkin, S. N. (2006): «La naturaleza del cambio léxico», en De Bustos Tovar, J. J. y Girón Alconchel, J. L. (eds.), Actas del VI Congreso Internacional de Historia de la Lengua Española, Madrid, Arco/Libros, pp. 67-84.

García de Diego, V. (1985): Diccionario etimológico español e hispánico, 2ª ed., Madrid, Espasa-Calpe.

Fisher, C. D. (ed.) (1906): Cornelii Taciti Annalium ab excessu diui Augusti libri, Óxford, Clarendon.

Iribarren, J. M. (1994): El porqué de los dichos, 7ª ed., Pamplona, Gobierno de Navarra.

Maldonado González, C. (dir.) (1996): Clave: diccionario de uso del español actual, Madrid, SM.

Moliner, M. (1998): Diccionario de uso del español, $2^{\underline{a}}$ ed., Madrid, Gredos.

PagÉs, A. de (1902): Gran diccionario de la lengua castellana, continuado y completado desde el tomo IV por J. Pérez de Hervás, 5 vols., Madrid, Sucesores de Rivadeneyra.

Pastoureau, M. (2000): Bleu. Histoire d'une couleur, París, Seuil.

Real Academia Española (2001): Diccionario de la Lengua Española (DRAE), $22^{\mathrm{a}}$ ed., Madrid, Espasa-Calpe.

ReY, A. (dir.) (1998): Dictionnaire historique de la langue française, París, Le Robert.

- (dir.) 2005: Dictionnaire culturel en langue française, París, Le Robert.

Sanmartí Boncompte, F. (1951): Tácito en España, Madrid, CSIC.

Seco, M., ANDrÉs, O. y RAmos, G. (1999): Diccionario del español actual, 2 vols., Madrid, Aguilar.

- (2004): Diccionario fraseológico documentado del español actual, Madrid, Aguilar.

Simpson, J. A. y WeInER, E. S. C. (prep.) (1989): The Oxford English Dictionary, 2a ed., 20 vols., Óxford, Clarendon Press.

WeStRIn, Th. (dir.) (1896): Nordisk familjebok, Konversationslexikon och Realencyklopedi, Estocolmo: C. \& E. Gernandts förlagsaktiebolag, 19 Supplement (A-Böttiger). En Internet: <http://runeberg.org/nfas/>. 